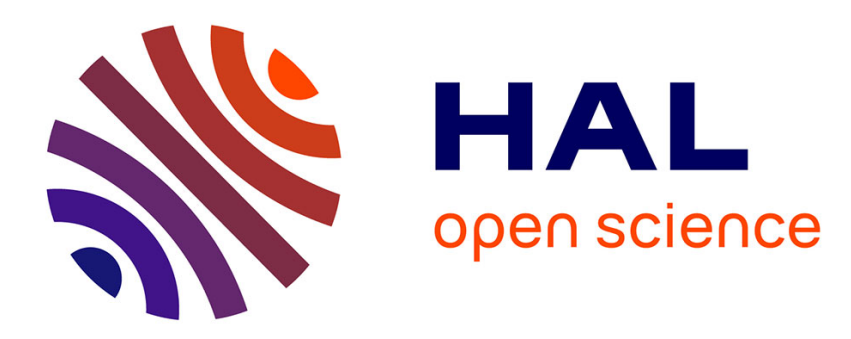

\title{
PCR et paléogénétique : pour le meilleur et pour le pire Eva-Maria Geigl
}

\section{To cite this version:}

Eva-Maria Geigl. PCR et paléogénétique : pour le meilleur et pour le pire. Bulletin de l'Académie Nationale de Médecine, 2021, 205 (4), pp.389-395. 10.1016/j.banm.2020.12.022 • hal-03377083

\section{HAL Id: hal-03377083 \\ https://hal.science/hal-03377083}

Submitted on 14 Oct 2021

HAL is a multi-disciplinary open access archive for the deposit and dissemination of scientific research documents, whether they are published or not. The documents may come from teaching and research institutions in France or abroad, or from public or private research centers.
L'archive ouverte pluridisciplinaire HAL, est destinée au dépôt et à la diffusion de documents scientifiques de niveau recherche, publiés ou non, émanant des établissements d'enseignement et de recherche français ou étrangers, des laboratoires publics ou privés. 
Bull Acad Natl Med 205 (2021) 389-395

https://doi.org/10.1016/j.banm.2020.12.022

0001-4079/@ 2021 l'Académie nationale de médecine

REVUE GÉNÉRALE

PCR et paléogénétique: pour le meilleur et pour le pire

PCR and paleogenetics : for best and for worst

Eva-Maria Geigl

eva-maria.geigl@ijm.fr

Université de Paris, CNRS, Institut Jacques Monod

Mots clés : ADN ancien, PCR, paléogénétique, contamination

Keywords : ancient DNA, PCR, paleogenetics, contamination 


\section{Résumé}

Au milieu des années 1980, l'extraction et l'analyse de l'ADN préservé dans des vestiges biologiques du passé ont donné des premiers résultats, entérinant la naissance du domaine de la paléogénétique. C'est grâce à l'invention de la PCR que cette nouvelle discipline a pu évoluer et récolter ses premiers succès. Néanmoins, la nature dégradée de l'ADN ancien et la puissance de la méthode de la PCR ont aussi abouti à de nombreux artefacts dus à la contamination avec l'ADN moderne qui ont failli tuer ce nouveau domaine à la fin des années 1990. L'application de procédures expérimentales rigoureuses et le développement de méthodes de décontamination et de prévention des contaminations ont ensuite permis la renaissance de la paléogénétique avant que le séquençage massivement parallèle n'ait rendu possible l'obtention d'information génomique d'individus anciens et l'essor du domaine.

\section{Abstract}

In the middle of the 1980s, extraction and analysis of DNA preserved in biological remains yielded the first results giving rise to a new scientific field, paleogenetics. Its first successes were obtained thanks to the advent of PCR. Yet, the degraded nature of ancient DNA and the power of PCR also led to numerous artefacts owing to contamination with modern DNA that have almost killed this new field at the end of the 1990s. Strict experimental procedures and the development of methods of decontamination and contamination prevention allowed the revival of the field. Recently, genomewide analyses of ancient individuals through next-generation sequencing led to the unfolding of paleogenetics.

\section{Naissance de la paléogénétique}

Ressusciter des organismes ayant vécu il y a longtemps est un rêve partagé par chercheurs et grand public qui a culminé en 1993 avec le passage à l'écran d'un roman de science-fiction : Jurassic Park [1, 2]. L'auteur de ce roman s'était inspiré de la naissance d'un nouveau domaine scientifique, la paléogénétique qui extrait et analyse l'ADN ancien préservé dans des vestiges biologiques du passé. Ce domaine a vu le jour en 1984 quand R. Higuchi et ses collègues du laboratoire d'A.C. Wilson à 
l'université de Berkeley, USA, ont pour la première fois analysé I'ADN d'un quagga, un équidé taxidermisé [3]. Ils ont utilisé pour cette percée la technique du clonage moléculaire. Cette analyse a requis une quantité considérable d'ADN et sa réussite n'a été possible que parce que ce spécimen n'était vieux que d'environ 140 ans et l'ADN était bien préservé, probablement grâce à la procédure de taxidermisation. Un an après, le clonage du gène HLA d'une momie égyptienne a été publié [4]. Et bien qu'il soit généralement reconnu aujourd'hui, même par son auteur [5], que ce furent des molécules d'ADN contaminant moderne qui ont été analysées dans cette étude, elle n'a jamais été rétractée. La méthode du clonage moléculaire aurait sérieusement limité cette nouvelle discipline scientifique qui serait probablement restée cryptique s'il n'y avait pas eu, la même année, une publication dans la revue «Science » [6] basée sur une invention de Kary Mullis qui a révolutionné la recherche en biologie : la réaction de polymérisation en chaîne, PCR [7].

Cette nouvelle approche a été la véritable accoucheuse du domaine de la paléogénétique. Elle a été immédiatement adoptée par les chercheurs du laboratoire d'A.C. Wilson à l'université de Berkeley [8] et en 1989, un article fondateur a été publié par le jeune post-doc qui s'était fait une réputation avec son analyse du gène HLA de la momie égyptienne, Svante Pääbo. Cet article décrivait la première caractérisation de l'ADN ancien et des approches méthodologiques pour son analyse, à savoir son extraction à partir de tissus anciens, dans la plupart des cas des os et des dents enfouis dans le sol, mais parfois aussi des cheveux, poils, peaux etc., sa caractérisation et son amplification enzymatique [9]. Cette étude a entériné le rôle de Svante Pääbo comme " père » de la paléogénétique et a eu un effet catalyseur pour d'autres chercheurs qui ont accepté le défi méthodologique de l'analyse de l'ADN ancien.

\section{Les défis méthodologiques de l'analyse de l'ADN ancien}

De quelle nature est ce défi? Les premières caractérisations de l'ADN ancien ont été effectuées à l'aide de la PCR et ont montré que l'ADN ancien est fortement dégradé [10] : dans la plupart des cas, le résultat de la PCR reste négatif si les amorces de PCR englobent plus de 100 paires de bases (pb). Cette 
dégradation qui aboutit, sauf cas exceptionnels, à une perte d'environ 99\% du matériel génétique est le résultat de l'action enzymatique post-mortem due aux nucléases intra-cellulaires et microbiennes ainsi que de l'hydrolyse chimique [11]. Néanmoins, puisque la dégradation chimique de l'ADN suit une cinétique de premier ordre, la taille des molécules d'ADN ancien se répartit selon une distribution de Poisson. Par conséquent, il se peut qu'une minuscule fraction des molécules d'ADN ancien préservées ait une taille plus grande. Ces molécules d'ADN peuvent servir comme matrice au cours de la PCR et peuvent donc être exploitées dans l'analyse, bien que la majorité des molécules d'ADN ait une taille nettement inférieure à 100 pb, et, comme l'ont montré plus tard les expériences du séquençage massivement parallèle, plutôt de l'ordre de 30 à 50 pb, voire encore moins. Par contre, ceci n'était pas connu à l'ère de la PCR car seulement des molécules porteuses de la séquence ciblée sont amplifiées. En plus de ces petites molécules d'ADN ancien extraites d'ossements ou d'autres tissus anciens sont co-extraits les acides nucléiques des organismes du sol dans lequel ils ont été enfouis, c'est-à-dire, les bactéries, les archéobactéries, les champignons, les plantes à travers leurs racines, ainsi que les animaux comme les insectes et les vers. Les extraits de spécimens anciens contiennent donc un mélange très hétérogène d'acides nucléiques d'origine très diverses auquel on se réfère avec l'appellation d'ADN environnemental. De plus, I'hétérogénéité des extraits ne se limite pas aux acides nucléiques car les acides humiques et fulviques et d'autres substances chimiques du sol sont aussi coextraits. Il y a parmi ces derniers des puissants inhibiteurs des enzymes, incluant l'ADN polymérase Taq indispensable pour la PCR. Une étape de purification s'impose donc avant que les extraits de spécimens anciens ne puissent être soumis à la PCR. Puisque la composition chimique des sols n'est pas connue, et hautement variable d'un échantillon à l'autre, et puisque les acides humiques constituent une classe chimique de molécules très hétérogène ce qui limite les possibilités de les éliminer, ces purifications ne sont pas toujours efficaces. Une partie des spécimens anciens résiste à toute analyse par les méthodes de la biologie moléculaire. L'imprédictibilité de la préservation de l'ADN et de l'élimination des inhibiteurs des enzymes limite les possibilités d'identification rigoureuse des causes des résultats négatifs de la paléogénétique. 
Une difficulté supplémentaire de l'analyse de l'ADN ancien provient de la transformation diagénétique et donc chimique des bases nucléotidiques dont une multitude a été caractérisée [12]. La plus fréquente est la désamination des cytosines [13] produisant des uraciles qui sont recopiés par l'ADN polymérase Taq comme adénines, le résultat étant une mésincorporation de nucléotides et un changement de la séquence, une transition de cytosine vers thymine ou, sur l'autre brin d'ADN, de guanine vers adénine [14] ce qui peut fausser la détermination de la séquence ancienne. La première solution proposée de la communauté scientifique a donc été de cloner les produits de PCR et de séquencer un certain nombre de clones, le plus le mieux, afin de pouvoir en déduire la séquence consensus. Plus tard, avec l'invention de la PCR quantitative en temps réel, certains laboratoires, dont le nôtre, ont préconisé la détermination du nombre initial des molécules d'ADN pour estimer la fiabilité de la séquence d'ADN obtenue qui, en tout état de cause, nécessitait l'analyse visuelle des électrophérogrammes pour évaluer l'hétérogénéité des séquences obtenues [15, 16].

\section{Authenticité des séquences d'ADN ancien}

Ceci montre une difficulté fondamentale de la recherche en ADN ancien : I'authenticité des résultats. Celle-ci est loin d'être triviale à cause de deux problèmes, le premier étant les transformations diagénétiques des bases nucléotidiques et le deuxième étant la contamination avec l'ADN moderne. En effet, la puissance de la PCR qui peut produire un milliard de molécules d'ADN à partir d'une molécule d'ADN initiale est donc bénédiction et malédiction. La plupart des vestiges biologiques anciens contiennent très peu d'ADN ancien, la moindre contamination des spécimens ou de leurs extraits peut s'avérer fatale pour l'authenticité des résultats car il ne sera pas possible de discriminer entre séquences d'ADN ancien et séquences d'ADN moderne si la source de contamination est proche de l'organisme analysé. Ceci est une véritable source d'erreurs pour l'analyse de spécimens humains car I'ADN humain contaminant est ubiquitaire. Ainsi s'explique la rareté des analyses de spécimens humains pendant les années 1990 . Le problème de la contamination est pourtant beaucoup plus étendu qu'admis par la communauté pendant cette période-là. En effet, non seulement l'ADN des 
chercheurs pose problème, mais aussi les produits des étapes PCR et de clonage qui ont précédé une nouvelle analyse d'un spécimen ancien, s'il s'agit de la même espèce ou d'une espèce proche, car ces produits de PCR sont dispersés aisément dans l'espace du laboratoire sous forme d'aérosol lors de la manipulation des solutions. Un faible nombre de produits de PCR est suffisant pour masquer le résultat véritable d'une PCR d'un spécimen ancien. Moins l'ADN est préservé dans un spécimen ancien, plus ce problème est grave. Pour réduire les risques de contamination, les laboratoires de paléogénétique se sont équipés de pièces confinées en surpression, avec séparation physique des espaces d'analyse préet post-PCR. Mais il est illusoire d'espérer d'obtenir une protection absolue avec cette seule séparation physique. Cette difficulté a suscité des procédures multiples et variées dont l'efficacité a rarement été évaluée rigoureusement et qui relevait parfois plus de la pensée magique que de l'approche scientifique (voir [17]). La meilleure protection est obtenue en diversifiant les approches pour minimiser indépendamment chaque source possible de contamination [17]. Une des solutions consiste, par exemple, à combiner approche physiques et enzymatiques : I'utilisation de dUTP à la place de dTTP lors de la PCR fait que les produits de cette réaction, les amplicons, sont des substrats pour l'enzyme uracil-N-glycosylase (UNG). Ces molécules seront alors digérées lors de la préincubation du mélange réactionnel avec l'UNG précédant chaque PCR. Ceci réduit en grande partie l'amplification des molécules d'ADN issues d'amplifications précédentes, qui peuvent être confondues avec les molécules d'ADN ancien [18]. Malheureusement, cette méthode utilisée largement en biologie moléculaire depuis les années 1990 [19] ne s'est jamais imposée dans le domaine de la recherche en paléogénétique avec le résultat qu'un nombre non-chiffré de données publiées sont probablement erronées.

Un problème supplémentaire découle de la manière dont sont produits dans les sociétés de biotechnologie les réactifs indispensables à toute expérimentation en biologie moléculaire. En effet, les enzymes sont stabilisées avec des protéines dont une source économique est l'albumine sérique bovine. Cette protéine est purifiée à partir de sang bovin et de l'ADN bovin est co-purifié en même temps, certes, à faible quantité, mais cette quantité est comparable à celle de l'ADN dans beaucoup 
d'extraits anciens. Les séquences d'ADN obtenues à partir d'ossements bovins anciens sont ainsi contaminées avec celles des bovins actuels, surtout ceux qui sont majoritaires dans les pays occidentaux, producteurs des réactifs de biologie moléculaire [20]. Notre équipe a montré comment on peut produire à partir de réactions de contrôles négatifs, c'est-à-dire sans ADN ajouté, des résultats ressemblant à ceux qu'on trouve dans des publications sur les bovins anciens [17]. On peut rencontrer un problème similaire si la gélatine a été utilisée pour stabiliser l'ADN polymérase Taq, raison pour laquelle nous avons pu produire des séquences porcines à partir de nos contrôles négatifs [17]. Ce problème peut aussi concerner l'ADN humain originaire d'employés des sociétés biotechnologiques qui vendent les enzymes, les dNTPs et les amorces d'ADN [21]. Notre équipe a montré que la contamination des amorces d'ADN fluctue en fonction de la politique d'embauche : il y a des sociétés où un roulement de personnel a été très peu fréquent pendant la période d'analyse alors que d'autres ont eu un roulement très élevé (E.A. Bennett T. Grange, E.-M. Geigl, inédit). Ce problème de contamination des réactifs ne s'arrête pas aux espèces animales domestiquées, mais peut aussi concerner des rongeurs, présents dans les usines biotechnologiques [22-25], des plantes utilisées pour produire la cellulose pour les colonnes de purification d'ADN, ou encore des bactéries utilisées pour produire les enzymes [26].

Afin de pallier à ce problème de contaminations des réactifs, nous avons conçu une méthode multiéchelle combinant des procédures physiques (irradiation avec des rayons UV) et biochimiques (utilisation des nucléases thermolabiles) des réactifs grâce à laquelle ils peuvent être décontaminés à au moins 99\% [17]. La dimension multi-échelle est nécessaire car à chaque fois qu'une source de contamination avec de l'ADN exogène a été éliminée, on voyait apparaître une autre source moins importante qui était masquée par la source plus abondante. De plus, il a été nécessaire de combiner différentes méthodes car le traitement à courte distance avec des rayons UV, très efficace pour les tampons et solutions minérales, n'est pas possible pour les enzymes qui sont inactivées par ce traitement. Les dNTPs, quant à eux, ne peuvent pas être décontaminés avec des rayons UV à cause de 
leur absorption de ces rayons. Chaque traitement n'étant pas efficace à $100 \%$, la combinaison de différentes méthodes permet de s'approcher très nettement de cette valeur idéale [17].

\section{La paléogénétique et la PCR : chance et menace}

Tous ces traitements et précautions sont nécessaires pour prévenir la contamination, mais ils ont été développés au cours du temps et trop souvent ignorés. La PCR a donc été bénédiction et malédiction de la recherche en ADN ancien, les deux aspects étant liées à sa puissance qui a fait naître le domaine au début des années 1990 et qui a failli le faire disparaître à la fin de cette décennie. Malgré quelques études publiées dont la véracité n'a pas été mise en doute, comme la caractérisation de l'ADN mitochondrial d'un mammouth [27], d'un ours des cavernes [28], de lapins [29] ainsi qu'une panoplie d'autres qui ont tous eu la vertu d'éclairer la phylogénie des taxons correspondants, il y a eu des études qui ont suscité des vagues d'enthousiasme dans l'opinion publique mais qui se sont avérées erronées car elles étaient dues à la contamination. Un des cas les plus spectaculaires responsables de cette déception dans ce nouveau domaine de la paléogénétique a été une publication en 1994 qui décrivait la séquence de l'ADN mitochondrial d'un dinosaure [30] qui plus tard s'est avéré correspondre à la séquence d'une insertion nucléaire ancienne d'un mitogénome dans le génome humain [31, 32]. La réanalyse d'une séquence d'ADN prétendument originaire d'un œuf de dinosaure du Crétacé vieux de 70 millions d'années [33] a montré qu'il s'agissait de la séquence d'un champignon [34]. D’autres exemples d'artefacts ont été le séquençage de l'ADN d'une termite piégée dans l'ambre datant de I'Oligo- ou Miocène [35], et d'un charançon dans l'ambre âgé de 135-120 millions d'années [36], ainsi que la supposée réanimation et séquençage de spores bactériennes récupérées à partir de l'ambre vieux de 25 à 40 millions d'années [37], dont les réanalyses et les efforts de réplication sont tous restées infructueux [38]. Une grande étude de nombreux spécimens préservés dans l’ambre a conclu que l'ADN n'est pas préservé dans ce matériel [39]. Ceci a aussi jeté le doute sur la première des publications d'ADN «antediluvien », la description d'une séquence d'ADN d'un chloroplaste obtenue à partir d'une feuille de magnolia datant du Miocène [40]. Bien que ces cas spectaculaires aient 
immédiatement été repérés et mis en doute à cause de leurs très vieux âges, d'autres cas, moins spectaculaires et moins vieux, sont restés inaperçus. II n'est donc pas exagéré de postuler qu'il reste dans la littérature un certain nombre de résultats partiellement ou complètement erronés et qui sont parfois difficiles à débusquer car toutes les études ne peuvent pas être reproduites faute d'accès aux échantillons analysés.

A la fin des années 1990, les paléogénéticiens ont été suffisamment alertés pour songer à des remèdes. Des listes de garde-fous ont été publiées, la plus important étant celui de la reproduction des résultats par un autre laboratoire (e.g., [41]). Cette règle a été pendant longtemps un impératif pour toute publication, mais elle n'était pas suffisante pour empêcher la publication de résultats erronés. Même la première séquence de la région hypervariable mitochondrial néandertalienne obtenue à partir du spécimen de Feldhofer en Allemagne, une découverte d'une énorme importance, possédaient des erreurs qui ont été reproduites dans le laboratoire ayant fait la réplication [42] comme on a pu s'en apercevoir quand le même laboratoire a publié la séquence du génome entier de ce Néandertalien en utilisant l'approche de séquençage massivement parallèle [43]. En effet, le transfert d'échantillons et d'amorces d'un laboratoire à un autre est susceptible de permettre aussi le transfert des contaminations.

Le risque de contamination augmente avec la rareté des molécules d'ADN endogène présentes dans un extrait ancien. Le facteur le plus important reconnu permettant la préservation de l'ADN étant la température, les spécimens préservés dans le pergélisol et dans les régions du Grand Nord ont livré des résultats génétiques plus fiables. Ainsi a été séquencé le cytochrome $b$ mitochondrial d'un mammouth permettant son analyse phylogénétique [44]. II a aussi été possible de reconstruire le paléoenvironnement au Groenland il y a environ 800000 à 450000 ans grâce à l'analyse de pollens et des sédiments piégés dans la glace [45], ou encore d'étudier les dynamiques populationnelles de la mégafaune du Grand Nord (mammouth, rhinocéros laineux, bison, bœuf musqué, renne, cheval) en réponse aux changements climatiques et environnementaux et l'action anthropique [46]. Par contre, 
des doutes subsistent sur de nombreuses publications concernant l'analyse paléogénétique d'individus humains archéologiques car il a été impossible de prouver l'authenticité des résultats.

\section{La PCR quantitative en temps réel}

L'invention de la PCR quantitative en temps réel (PCRq ; [47]) a permis de quantifier le nombre de molécules d'ADN initialement présentes dans un extrait fossile afin d'évaluer la probabilité que les séquences d'ADN obtenues soient authentiques [15]. En effet, plus le nombre de molécules d'ADN initiales est important, plus est élevée la probabilité que les séquences obtenues l'aient été à partir de ces molécules anciennes. Plus le nombre de molécules d'ADN ancien est faible, plus est élevée la probabilité que les molécules d'ADN synthétisées à partir des molécules d'ADN ancien matrices soient affectées pendant les premiers cycles de la PCR par des mésincorporations de bases. De plus, cette méthode permet également d'apprécier l'ampleur de l'inhibition de l'ADN polymérase Taq [15]. Cette procédure a donc rendu la production de séquences d'ADN ancien plus fiable et a été utilisée par notre laboratoire pour des études de la phylogéographie d'animaux éteints ou en voie d'extinction, comme les ânes sauvages asiatiques et l'énigmatique hydrontin européen qui est représenté dans quelques peintures et gravures rupestres françaises [48]. Ces avantages de la PCRq peuvent la rendre encore utile même à l'époque de séquençage massivement parallèle des banques génomiques pour estimer le nombre initial des molécules d'ADN ainsi que le pouvoir inhibiteur des extraits [26].

\section{La place de la PCR à l'ère du séquençage massivement parallèle}

Nous avons aussi développé une méthode combinant puissance et sensibilité de la PCR avec efficacité du séquençage massivement parallèle (sur la plateforme lon Torrent ou Illumina) pour séquencer à des coûts relativement faibles un grand nombre d'échantillons en parallèle en s'appuyant sur le multiplexage des PCRs, la méthode "aMPlex Torrent» (ancient multiplex Torrent; [49]). Cette approche s'est avérée très puissante et nous l'avons utilisée pour analyser des rongeurs vieux d'au moins 40000 ans et préservés dans des grottes du Maroc [49], des parasites gastro-intestinaux des sites archéologiques [50], la diffusion dans l'Ancien Monde du chat depuis le Néolithique en Anatolie 
et l'Antiquité en Egypte [51], ou encore récemment l'analyse de la couleur de la robe des chevaux qui avaient une signification particulière pour les sociétés anciennes [52] et se sont diversifiées au cours de leur domestication [53]. Bien que généralement remplacée par l'approche de la capture de séquences d'ADN en solution et leur séquençage massivement parallèle [54], nous utilisons toujours la méthode aMPlex Torrent, maintenant adaptée à la plateforme de séquençage Illumina MiSeq, pour produire des séquences d'ADN qui résistent à la capture en solution.

La puissance de la PCR ciblée est supérieure à celle du séquençage massivement parallèle, et elle peut détecter des traces difficilement détectables par un séquençage aléatoire à trop faible couverture. Par exemple, l'analyse par PCR d'un coprolithe originaire d'une couche datant du Pléistocène dans une grotte du Caucase a produit une séquence mitochondriale d'une hyène brune alors que celle-ci est actuellement endémique en Afrique du Sud et n'a jamais été trouvée dans le Caucase. L'analyse par séquençage massivement parallèle d'une banque d'ADN produite à partir de ce coprolithe n'a pas permis de détecter une quantité significative d'ADN correspondant clairement au génome de l'hyène brune. Ceci montre que la PCR a été, dans ce cas, plus sensible que le séquençage aléatoire qui s'est révélé à à trop faible couverture. Par contre, comment expliquer la présence de traces d'ADN d'hyène d'Afrique du Sud dans le Caucase au Pléistocène ? Comme nous n'avions jamais analysé d'hyène d'Afrique du Sud par PCR avant d'obtenir cet échantillon, nous pouvions exclure une contamination au laboratoire. Par contre, il s'est avéré ensuite que ce coprolithe a transité par un laboratoire d'Afrique du sud où des crottes de hyènes modernes ont aussi été traitées, et que les mêmes ustensiles, bien que lavés entre chaque étape, ont été utilisés plusieurs semaines auparavant pour découper les crottes modernes et les coprolithes. La séquence d'hyène obtenue devait donc provenir d'une contamination de l'échantillon par de l'ADN d'hyène brune moderne porté par des ustensiles mal décontaminés [55]. Ainsi, la plus grande sensibilité de la PCR ciblée peut être parfois un avantage, mais elle nécessite toujours la plus grande vigilance, car ultra haute sensibilité signifie aussi risque élevé de détecter des contaminations. 


\section{La paléogénomique, stade adulte de la paléogénétique}

Depuis 2006, avec l'avènement du séquençage massivement parallèle, le domaine de la paléogénétique s'est transformé en paléogénomique [56]. Cette nouvelle approche repose sur la construction de banques d'ADN permise par la ligation d'adaptateurs aux extrémités des molécules d'ADN qui seront ensuite amplifiées par PCR, un processus appelé LM-PCR (« ligation-mediated PCR »). Toutes les molécules d'ADN contenues dans une banque d'ADN seront ensuite séquencées par une approche de séquençage aléatoire (« shotgun-sequencing »). Cette dernière approche a deux grands avantages sur l'approche basée sur la PCR ciblée: 1) elle permet de déduire la séquence des génomes entiers d'organismes éteints, par exemple des populations humaines inconnues auparavant (voir plus loin); 2) elle permet de réduire les problèmes de contaminations puisqu'on amplifie les molécules d'ADN ancien à partir d'adaptateurs qu'on a ligaturés à toutes les molécules d'ADN présentes dans un extrait ancien sans qu'il soit nécessaire de cibler une taille minimum. La diversité des séquences amplifiées réduit l'amplification de chaque molécule d'ADN individuelle et donc le risque qu'elle puisse contaminer les expériences ultérieures. Par contre, il reste, là aussi, le risque de contaminations croisées entre échantillons et adaptateurs portant des index ce qui oblige les paléogénomiciens d'utiliser des marquages des molécules dans leurs banques d'ADN avec des doubles index uniques. Néanmoins, pour pouvoir séquencer les banques d'ADN construites à partir d'extraits anciens, il faut les amplifier en utilisant la PCR et donc la prudence et la rigueur expérimentale sont toujours nécessaires pour minimiser le risque de contamination. Ce risque redevient particulièrement élevé dans le cas de l'utilisation de la capture des séquences à partir des banques génomiques car elle est accompagnée d'étapes d'amplification des molécules capturées.

Bien que l'analyse paléogénomique reste un défi méthodologique, elle a apporté un grand nombre de résultats inattendus qui n'auraient pas pu être obtenus par d'autres analyses plus conventionnelles. Ainsi, il a été possible de caractériser les métissages entre les Humains anatomiquement modernes et des Humains archaïques, comme les Dénisoviens, une population identifiée uniquement par son 
génome, et les Néandertaliens [57-61], et d'en déduire les parties génomiques que nous avons héritées de ces populations archaïques. En effet, l'introgression adaptative a probablement joué un rôle important pour permettre le succès du peuplement de l'Eurasie par les premières populations d' $H$. sapiens. La paléogénomique a aussi mis en évidence des migrations de populations d'origine procheorientale pendant le Néolithique il y a 8500 ans, et il y a 4500 ans, à l'Âge du Bronze, de populations provenant des steppes pontiques $[62,63]$. Dans ces deux cas, les populations migrantes se sont métissées avec les populations autochtones, un processus qui a constitué les génomes des Européens des périodes suivantes jusqu'à nos jours, entre autres, en France [64].

La paléogénomique permet aussi d'éclairer les dynamiques des populations d'animaux sauvages, comme les bisons [54], mais aussi les processus de domestication, comme ceux des chevaux [52, 53, 65 ], des chiens [66], des chèvres [67] ou encore des cochons [68].

\section{Conclusion}

Pour conclure, la PCR fut l'approche qui a permis la naissance du domaine de la paléogénétique et de voir se réaliser ce rêve ancien de pouvoir remonter dans le temps et analyser le monde d'avant. Elle a caractérisé l'enfance de ce domaine et produit des moments de progrès et de bonheur autant que des maladies. L'âge de la maturité du domaine a été atteint avec l'invention du séquençage aléatoire massivement parallèle, et c'est à partir de ce moment-là qu'il a pris son véritable essor en tant que paléogénomique. Les études paléogénomiques ont continué d'éclairer l'évolution des espèces. La production de résultats plus fiables qu'avec la paléogénétique a rendu possible l'analyse des êtres humains. Ainsi, les études paléogénomiques ont mis en évidence des espèces et populations humaines inconnues, des métissages et des migrations inconnus, et elles ont ainsi révolutionné la paléoanthropologie. Elles ont aussi changé notre vision de la domestication des animaux et, de manière générale, les processus d'adaptation à des nouveaux environnements. Finalement, elles ont aussi éclairé l'évolution des bactéries pathogènes ainsi que quelques-unes des plus grandes pandémies 
qu'a subies l'humanité. Le domaine de la paléogénomique étant en plein expansion, de très belles découvertes sont encore à venir.

\section{Remerciements}

Je remercie Francis Galibert et Patrick Netter de m'avoir invitée à participer à cette séance de

l'Académie de Médecine dédiée à la mémoire de Kary Mullis, inventeur de la PCR. Je remercie Thierry

Grange pour sa relecture critique de cet article.

L'auteure ne déclare aucun conflit d'intérêt.

\section{Bibliographie}

[1] Crichton M. Jurassic Park. New York : Alfred A. Knopf, 1990.

[2] Spielberg S. Jurassic Park. 1993.

[3] Higuchi R, Bowman B, Freiberger M, Ryder OA, Wilson AC. DNA sequences from the quagga, an extinct member of the horse family. Nature 1984;312: 282-4.

[4] Pääbo S. Molecular cloning of Ancient Egyptian mummy DNA. Nature 1985;314: 644-5.

[5] Pääbo S. Neanderthal Man. In Search of Lost Genomes. New York : Basic Books, 2014.

[6] Saiki RK, Scharf S, Faloona F, Mullis KB, Horn GT, Erlich HA, et al. Enzymatic amplification of b-globin genomic sequences and restriction site analysis for diagnosis of sickle cell anemia. Science 1985;230: 1350-4.

[7] Mulllis KB. Process for amplifying nucleic acid sequences. Brevet : 4683 202. USPTO, USA.

[8] Pääbo S, Gifford JA, Wilson AC. Mitochondrial DNA sequences from a 7000 -year old brain. Nucleic Acids Res 1988;16: 9775-87.

[9] Pääbo S. Ancient DNA: extraction, characterization, molecular cloning, and enzymatic amplification. Proc Natl Acad Sci U S A 1989;86: 1939-43.

[10] Pääbo S, Higuchi RG, Wilson AC. Ancient DNA and the polymerase chain reaction. The emerging field of molecular archaeology. J Biol Chem 1989;264: 9709-12.

[11] Lindahl T. Instability and decay of the primary structure of DNA. Nature 1993;709-15.

[12] Höss $M$, Jaruga P, Zastawny TH, Dizdaroglu M, Paabo S. DNA damage and DNA sequence retrieval from ancient tissues. Nucleic Acids Res 1996;24: 1304-7.

[13] Lindahl T, Nyberg B. Heat-induced deamination of cytosine residues in deoxyribonucleic acid. Biochemistry 1974;13: 3405-10.

[14] Hofreiter M, Jaenicke V, Serre D, Haeseler Av A, Pääbo S. DNA sequences from multiple amplifications reveal artifacts induced by cytosine deamination in ancient DNA. Nucl. Acids Res. 2001;29: 4793-9.

[15] Pruvost M, Geigl E-M. Real-time quantitative PCR to assess the authenticity of ancient DNA amplification. J. Arch. Science 2004;31: 1191-7.

[16] Pruvost M, Schwarz R, Bessa Correia V, Champlot S, Grange T, Geigl E-M. DNA diagenesis and palaeogenetic analysis: critical assessment and methodological progress. Palaeogeogr. Palaeoclimatol. Palaeoecol. 2008;266: 211-9. 
[17] Champlot S, Berthelot C, Pruvost M, Bennett EA, Grange T, Geigl EM. An efficient multistrategy DNA decontamination procedure of PCR reagents for hypersensitive PCR applications. PLoS One 2010;5: e13042.

[18] Pruvost M, Grange T, Geigl E-M. Minimizing DNA contamination by using UNG-coupled quantitative real-time PCR on degraded DNA samples: application to ancient DNA studies. BioTechniques 2005;38: 569-75.

[19] Longo MC, Berninger MS, Hartley JL. Use of uracil DNA glycosylase to control carry-over contamination in polymerase chain reactions. Gene 1990;93: 125-8.

[20] Leonard JA, Shanks O, Hofreiter M, Kreuz E, Hodges L, Ream W, et al. Animal DNA in PCR reagents plagues ancient DNA research. J. Arch. Science 2007;34: 1361-6.

[21] Deguilloux MF, Ricaud S, Leahy R, Pemonge MH. Analysis of ancient human DNA and primer contamination: One step backward one step forward. Forensic Sci Int 2011;102-8.

[22] Erlwein O, Robinson MJ, Dustan S, Weber J, Kaye S, McClure MO. DNA extraction columns contaminated with murine sequences. PLoS One 2011;6: e23484.

[23] Kearney MF, Spindler J, Wiegand A, Shao W, Anderson EM, Maldarelli F, et al. Multiple sources of contamination in samples from patients reported to have XMRV infection. PLoS One 2012;7: e30889.

[24] Oakes B, Tai AK, Cingoz O, Henefield MH, Levine S, Coffin JM, et al. Contamination of human DNA samples with mouse DNA can lead to false detection of XMRV-like sequences. Retrovirology 2010;7: 109.

[25] Zheng $\mathrm{H}$, Jia $\mathrm{H}$, Shankar A, Heneine W, Switzer WM. Detection of murine leukemia virus or mouse DNA in commercial RT-PCR reagents and human DNAs. PLoS One 2011;6: e29050.

[26] Gorgé O, Bennett EA, Massilani D, Daligault J, Pruvost M, Geigl EM, et al. Analysis of Ancient DNA in Microbial Ecology. Methods in molecular biology 2016;1399: 289-315.

[27] Hagelberg E, Thomas MG, Cook CE, Jr., Sher AV, Baryshnikov GF, Lister AM. DNA from ancient mammoth bones. Nature 1994;370: 333-4.

[28] Hänni C, Laudet V, Stehelin D, Taberlet P. Tracking the origins of the cave bear (Ursus spelaeus) by mitochondrial DNA sequencing. Proc Natl Acad Sci U S A 1994;91: 12336-40.

[29] Hardy C, Callou C, Vigne JD, Casane D, Dennebouy N, Mounolou JC, et al. Rabbit mitochondrial DNA diversity from prehistoric to modern times. J Mol Evol 1995;40: 227-37.

[30] Woodward SR, Weyand NJ, Bunnell M. DNA sequence from Cretaceous period bone fragments. Science 1994;266: 1229-32.

[31] Hedges SB, Schweitzer MH. Detecting dinosaur DNA. Science 1995;268: 1191-2; discussion 4.

[32] Zischler H, Hoss M, Handt O, von Haeseler A, van der Kuyl AC, Goudsmit J. Detecting dinosaur DNA. Science 1995;268: 1192-3; author reply 4.

[33] An C-C, Li Y, Zhu Y-X. Molecular cloning and sequencing of the 18s rDNA from spe- cialized dinosaur egg fossil found in Xixia Henan, China. Acta Sci. Nat. Univ. Pekinensis 1995;31: 140-7.

[34] Wang HL, Yan ZY, Jin DY. Reanalysis of published DNA sequence amplified from cretaceous dinosaur egg fossil. Molecular Biology and Evolution 1997;14: 589-91.

[35] DeSalle R, Gatesy J, Wheeler W, Grimaldi D. DNA sequences from a fossil termite in Oligo-Miocene amber and their phylogenetic implications. Science 1992;257: 1933-6.

[36] Cano RJ, Poinar HN, Pieniazek NJ, Acra A, Poinar GO, Jr. Amplification and sequencing of DNA from a 120-135-million-year-old weevil. Nature 1993;363: 536-8.

[37] Cano RJ, Borucki MK. Revival and identification of bacterial spores in 25- to 40-million- year-old Dominican amber. Science 1995;268: 1060-4.

[38] Walden KKO, Robertson HM. Ancient DNA from amber fossil bees? Mol. Biol. Evol. 1997;14: 10757.

[39] Austin JJ, Ross AJ, Smith AB, Fortey RA, Thomas RH. Problems of reproducibility--does geologically ancient DNA survive in amber-preserved insects? Proc R Soc Lond B Biol Sci 1997;264: 467-74.

[40] Golenberg EM, Giannasi DE, Clegg MT, Smiley CJ, Durbin M, Henderson D, et al. Chloroplast DNA sequence from a miocene Magnolia species. Nature 1990;344: 656-8.

[41] Cooper A, Poinar HN. Ancient DNA: do it right or not at all. Science 2000;289: 1139. 
[42] Krings M, Stone A, Schmitz RW, Krainitzki H, Stoneking M, Pääbo S. Neandertal DNA sequences and the origin of modern humans. Cell 1997;90: 19-30.

[43] Green RE, Krause J, Briggs AW, Maricic T, Stenzel U, Kircher M, et al. A draft sequence of the Neandertal genome. Science 2010;328: 710-22.

[44] Debruyne R, Barriel V, Tassy P. Mitochondrial cytochrome b of the Lyakhov mammoth (Proboscidea, Mammalia): new data and phylogenetic analyses of Elephantidae. Molecular phylogenetics and evolution 2003;26: 421-34.

[45] Willerslev E, Cappellini E, Boomsma W, Nielsen R, Hebsgaard MB, Brand TB, et al. Ancient biomolecules from deep ice cores reveal a forested southern Greenland. Science 2007;317: 111-4.

[46] Lorenzen ED, Nogues-Bravo D, Orlando L, Weinstock J, Binladen J, Marske KA, et al. Speciesspecific responses of Late Quaternary megafauna to climate and humans. Nature 2011;479: 359-64.

[47] Higuchi R, Fockler C, Dollinger G, Watson R. Kinetic PCR analysis: Real-time monitoring of DNA amplification reactions. Biotechnology (NY) 1993;11: 1026-30.

[48] Bennett EA, Champlot S, Peters J, Arbuckle BS, Guimaraes S, Pruvost M, et al. Taming the late Quaternary phylogeography of the Eurasiatic wild ass through ancient and modern DNA. PLoS One 2017;12: e0174216.

[49] Guimaraes S, Pruvost M, Daligault J, Stoetzel E, Bennett EA, Cote NM, et al. A cost-effective highthroughput metabarcoding approach powerful enough to genotype $\sim 44000$ year-old rodent remains from Northern Africa. Mol Ecol Resour 2017;17: 405-17.

[50] Coté NM, Daligault J, Pruvost M, Bennett EA, Gorgé O, Guimaraes S, et al. A New High-Throughput Approach to Genotype Ancient Human Gastrointestinal Parasites. PLoS One 2016;11: e0146230.

[51] Ottoni C, Van Neer W, De Cupere B, Daligault J, Guimaraes S, Peters J, et al. The palaeogenetics of cat dispersal in the ancient world. Nature Ecology and Evolution 2017;1.

[52] Librado P, Gamba C, Gaunitz C, Der Sarkissian C, Pruvost M, Albrechtsen A, et al. Ancient genomic changes associated with domestication of the horse. Science 2017;356: 442-5.

[53] Guimaraes S, Arbuckle BS, Peters J, Adcock SE, Buitenhuis H, Chazin H, et al. Ancient DNA shows domestic horses were introduced in the southern Caucasus and Anatolia during the Bronze Age. Science Advances 2020.

[54] Massilani D, Guimaraes S, Brugal JP, Bennett EA, Tokarska M, Arbogast RM, et al. Past climate changes, population dynamics and the origin of Bison in Europe. BMC biology 2016;14: 93.

[55] Bennett EA, Gorgé O, Grange T, Fernández-Jalvo Y, Geigl E-M. Coprolites, Paleogenomics and Bone Content Analysis. in: Fernández-Jalvo Y, King T, Yepiskoposyan L, Andrews P (Eds.) Azokh Cave and the Transcaucasian Corridor: Springer, 2016, pp. 271-86

[56] Noonan JP, Coop G, Kudaravalli S, Smith D, Krause J, Alessi J, et al. Sequencing and analysis of Neanderthal genomic DNA. Science 2006;314: 1113-8.

[57] Reich D, Green RE, Kircher M, Krause J, Patterson N, Durand EY, et al. Genetic history of an archaic hominin group from Denisova Cave in Siberia. Nature 2010;468: 1053-60.

[58] Reich D, Patterson N, Kircher M, Delfin F, Nandineni MR, Pugach I, et al. Denisova admixture and the first modern human dispersals into Southeast Asia and Oceania. Am J Hum Genet 2011;89: 51628.

[59] Meyer M, Kircher M, Gansauge MT, Li H, Racimo F, Mallick S, et al. A high-coverage genome sequence from an archaic Denisovan individual. Science 2012;338: 222-6.

[60] Prüfer K, Racimo F, Patterson N, Jay F, Sankararaman S, Sawyer S, et al. The complete genome sequence of a Neanderthal from the Altai Mountains. Nature 2014;505: 43-9.

[61] Prüfer K, de Filippo C, Grote S, Mafessoni F, Korlevic P, Hajdinjak M, et al. A high-coverage Neandertal genome from Vindija Cave in Croatia. Science 2017;358: 655-8.

[62] Lazaridis I, Nadel D, Rollefson G, Merrett DC, Rohland N, Mallick S, et al. Genomic insights into the origin of farming in the ancient Near East. Nature 2016;536: 419-24.

[63] Haak W, Lazaridis I, Patterson N, Rohland N, Mallick S, Llamas B, et al. Massive migration from the steppe was a source for Indo-European languages in Europe. Nature 2015;522: 207-11. 
[64] Brunel S, Bennett EA, Cardin L, Garraud D, Barrand Emam H, Beylier A, et al. Ancient genomes from present-day France unveil 7,000 years of its demographic history. Proc Natl Acad Sci U S A 2020;117: 12791-8.

[65] Fages A, Hanghoj K, Khan N, Gaunitz C, Seguin-Orlando A, Leonardi M, et al. Tracking Five Millennia of Horse Management with Extensive Ancient Genome Time Series. Cell 2019;177: 1419-35 e31.

[66] Bergström A, Frantz L, Schmidt R, Ersmark E, Lebrasseur O, Girdland-Flink L, et al. Origins and genetic legacy of prehistoric dogs. Science 2020;370: 557-64.

[67] Daly KG, Maisano Delser P, Mullin VE, Scheu A, Mattiangeli V, Teasdale MD, et al. Ancient goat genomes reveal mosaic domestication in the Fertile Crescent. Science 2018;361: 85-8.

[68] Frantz LA, Mullin VE, Pionnier-Capitan M, Lebrasseur O, Ollivier M, Perri A, et al. Genomic and archaeological evidence suggest a dual origin of domestic dogs. Science 2016;352: 1228-31. 